\title{
Design, history and results of the Thiazolidinedione Intervention with vitamin D Evaluation (TIDE) randomised controlled trial
}

\author{
The TIDE Trial Investigators
}

Received: 5 September 2011 / Accepted: 6 October 2011 /Published online: 29 October 2011

(C) Springer-Verlag 2011

\begin{abstract}
Aims/objective Conflicting data regarding cardiovascular effects of thiazolidinediones (TZDs) and extra-skeletal effects of vitamin D supported the need for a definitive trial. The Thiazolidinedione Intervention with vitamin D Evaluation (TIDE) trial aimed to assess the effects of TZDs (rosiglitazone and pioglitazone) on cardiovascular outcomes and the effects of vitamin D (cholecalciferol) on cancers and mortality.

Methods A large multicentre $3 \times 2$ factorial double-blind placebo-controlled randomised trial recruited from outpatient primary care and specialty clinics in 33 countries. From June 2009 to July $2010,1,332$ people with type 2 diabetes and other cardiovascular risk factors aged $\geq 50$ years whose $\mathrm{HbA}_{1 \mathrm{c}}$ was
\end{abstract}

The TIDE Trial Investigators Writing Committee Z. Punthakee and J. Bosch (Population Health Research Institute McMaster University, Hamilton, ON, Canada); G. Dagenais (Institut Universitaire de Cardiologie et de Pneumologie de Québec Université Laval, Québec, QC, Canada); R. Diaz (Instituto Cardiovascular de Rosario, Rosario, Argentina); R. Holman (Oxford Centre for Diabetes Oxford, UK); J. L. Probstfield (University of Washington Seattle, WA, USA); A. Ramachandran (India Diabetes Research Foundation Chennai, India); M. C. Riddle (Oregon Health \& Science University Portland, OR, USA); L. E. Rydén (Karolinska Institutet Stockholm, Sweden); B. Zinman (University of Toronto, Toronto, ON, Canada); R. Afzal, S. Yusuf and H. C. Gerstein (Population Health Research Institute, McMaster University, Hamilton, ON, Canada).

Electronic supplementary material The online version of this article (doi:10.1007/s00125-011-2357-4) contains peer-reviewed but unedited supplementary material, including a list of the TIDE Trial Investigators, which is available to authorised users.

The TIDE Trial Investigators $(\bowtie)$

c/o Z. Punthakee,

Population Health Research Institute, McMaster University,

237 Barton St E.,

Hamilton, ON, Canada L8L 2X2

e-mail: zubin.punthakee@mcmaster.ca
6.5-9.5\% (48-80 $\mathrm{mmol} / \mathrm{mol})$ when using two or fewer glucose-lowering drugs were randomised by a central computer system to placebo $(n=541)$, rosiglitazone 4 $8 \mathrm{mg}$ /day $(n=399)$ or pioglitazone $30-45 \mathrm{mg} /$ day $(n=392)$; 1,221 participants were randomised to placebo $(n=614)$ or vitamin D 1,000 IU/day $(n=607)$. Participants and all study personnel were blind to treatment allocation. The primary outcome for the TZD arm was the composite of myocardial infarction, stroke or cardiovascular death, and for the vitamin D arm it was cancer or all-cause death. All randomised participants were included in the primary analysis.

Results From the study design, 16,000 people were to be followed for approximately 5.5 years. However, the trial was stopped prematurely because of regulatory concerns after a mean of 162 days without consideration of the accrued data. In the TZD arm, the cardiovascular outcome occurred in five participants $(0.9 \%)$ in the placebo groups and three participants $(0.4 \%)$ in the TZD groups (two allocated to pioglitazone, one to rosiglitazone). In the vitamin $\mathrm{D}$ arm, the primary outcome occurred in three participants $(0.5 \%)$ in the placebo group and in two participants $(0.3 \%)$ receiving vitamin D. Adverse events were comparable in all groups.

Conclusions/interpretation Uncertainty persists regarding the clinically relevant risks and benefits of TZDs and vitamin $\mathrm{D}$ because of the early cancellation of this comprehensive trial.

Trial registration: ClinicalTrials.gov NCT00879970

Funding: The study was funded by GlaxoSmithKline.

Keywords Cardiovascular disease - Pioglitazone - Placebocontrolled randomised trial $\cdot$ Rosiglitazone $\cdot$ Type 2

diabetes · Vitamin D 


$\begin{array}{ll}\text { Abbreviations } \\ \text { ALT } & \text { Alanine aminotransferase } \\ \text { eGFR } & \text { Estimated GFR } \\ \text { FDA } & \text { Food and Drug Administration } \\ \text { TIDE } & \begin{array}{l}\text { Thiazolidinedione Intervention with vitamin D } \\ \end{array} \\ \text { Evaluation trial } \\ \text { TZD } & \text { Thiazolidinedione }\end{array}$

\section{Background}

The thiazolidinediones (TZDs) rosiglitazone and pioglitazone lower glucose levels without causing hypoglycaemia [1]. They also reduce many other cardiovascular risk factors including: incident diabetes [2, 3]; insulin resistance [4, 5]; blood pressure [6]; albuminuria [7]; renal disease [8,9]; inflammatory markers [10]; revascularisation after percutaneous coronary intervention [11]; and carotid [3, 12-14] and coronary atherosclerosis $[15,16]$. These observations and analyses of data from administrative databases in 2005 show that people prescribed TZDs may have fewer cardiovascular events or deaths than people prescribed other agents $[17,18]$ and suggest that TZDs may improve cardiovascular outcomes. This hypothesis gained support from trials showing that: (1) insulin-sensitising therapies (comprising mainly rosiglitazone plus metformin) had effects on mortality and cardiovascular events comparable with those of insulin-providing therapies in people with diabetes and proven coronary artery disease [19]; (2) the cardiovascular effects of rosiglitazone in combination with either metformin or a sulfonylurea were similar to those of metformin plus a sulfonylurea [20]; and (3) pioglitazone non-significantly reduced cardiovascular events compared with a placebo [21]. However, the limitations of the methods of the latter two trials [22-24], the higher risk of heart failure with TZDs [25], analyses of other administrative databases, and inconclusive meta-analyses of mainly small trials comprising few events [26-30] raised uncertainty regarding the cardiovascular safety of rosiglitazone and the effects of the TZDs as a class. Collectively, these observations highlighted the need for a definitive trial testing the hypothesis that TZDs may improve cardiovascular outcomes in patients with diabetes and other cardiovascular risk factors.

Emerging evidence suggests that type 2 diabetes is associated with low levels of vitamin D [31], and a growing body of evidence links vitamin D deficiency to many of the chronic diseases that occur in people with diabetes, including cancer [32] and cardiovascular disease [33, 34]. The possibility that vitamin D supplementation may reduce these risks was suggested by a recent meta-analysis of 18 randomised controlled trials in which a mean of $528 \mathrm{IU} /$ day of vitamin D reduced total mortality by $7 \%$ over a mean of
5.7 years [35]. This, and evidence of a neutral effect of 400 IU/day on cancers and cardiovascular outcomes [3638 ] and a beneficial effect of 1,100 IU/day on cancer risk [39], suggest that higher doses of vitamin D might improve health outcomes in people with diabetes.

The Thiazolidinedione Intervention with vitamin $\mathrm{D}$ Evaluation (TIDE) trial was designed to explicitly determine whether the TZDs and/or vitamin D can safely reduce clinically important outcomes. It was designed by an international scientific committee of ten experts in clinical trials, diabetes and cardiovascular disease plus a representative from the sponsor (GlaxoSmithKline - the manufacturer of rosiglitazone), with input from representatives of the US Food and Drug Administration (FDA) who approved the final design. Global implementation of TIDE was led by this group and 35 other experts. It was subsequently approved by a total of 33 regulatory agencies and 525 research ethics committees in 33 countries. Its progress and safety were monitored by an independent data-monitoring committee of five international experts. Notwithstanding these approvals and safeguards, there was ongoing public controversy regarding the safety of rosiglitazone [40], prompted by a US Senate Committee report [41], and an advisory board was convened by the FDA [42, 43]. On 21 July 2010, the FDA suspended recruitment into the trial, and on 23 September 2010 it required withdrawal of treatment for all participants enrolled in the TIDE trial. This paper reports the course of the TIDE trial and its accrued outcomes by treatment group in the context of these decisions.

\section{Methods}

TIDE was a $3 \times 2$ factorial double-blind randomised placebo-controlled trial. Volunteers were enrolled from primary care, diabetes and cardiology clinics if they had type 2 diabetes and an $\mathrm{HbA}_{1 \mathrm{c}}$ level ranging from $6.5 \%$ to $9.5 \%$ (48 to $80 \mathrm{mmol} / \mathrm{mol}$ ), were drug-naive or taking up to two non-insulin glucose-lowering medications, and were at risk of cardiovascular disease on the basis of: (1) age at least 50 years with a prior cardiovascular event; (2) age at least 55 years with documented arterial stenosis, albuminuria, ankle brachial index $<0.9$ or left ventricular hypertrophy; or (3) age at least 60 years with at least two risk factors (tobacco use, high LDL-cholesterol, low HDL-cholesterol or high triacylglycerols, hypertension or obesity). Key exclusion criteria were a cardiovascular event within 30 days before randomisation, history of pulmonary oedema, symptomatic heart failure (New York Heart Association class II-IV), known left ventricular ejection fraction below $40 \%$ or use of a loop diuretic, cancer diagnosed in the prior 3 years or active treatment for cancer (other than non-melanoma skin cancer or cervical carcinoma in situ), fracture in the prior year, known 
osteomalacia, or hypercalcaemia. The protocol and consent forms were approved by ethics committees at all recruiting centres, and all participants provided written informed consent.

After 3 weeks of active rosiglitazone and vitamin D (cholecalciferol) run-in, participants were randomised by a central phone-in computer system to placebo, pioglitazone $30 \mathrm{mg}$ daily or rosiglitazone $4 \mathrm{mg}$ daily at a 4:3:3 ratio. Doses were to be increased to pioglitazone $45 \mathrm{mg}$ daily or rosiglitazone $8 \mathrm{mg}$ daily by 12 months. Independent of their TZD allocation, participants were also randomised to placebo or vitamin D, 1,000 IU daily, in a 1:1 ratio. Due to manufacturing delays, the vitamin D study drug was not available at the start of the trial. Thus approximately $40 \%$ of the vitamin D participants were randomised to the vitamin $\mathrm{D}$ arm after randomisation to the TZD arm. The management of glucose levels and all other conditions was at the discretion of the local physician as informed by clinical practice guidelines and the relevant evidence; openlabel TZDs were not permitted. Study visits were conducted 2 and 6 months after randomisation and every 6 months thereafter.

The primary outcome measure for the TZD arm was the first occurrence of the composite of myocardial infarction, stroke or cardiovascular death, and for the vitamin D arm it was all-cause death or cancers requiring hospitalisation, chemotherapy or surgery. Other outcomes included a composite microvascular outcome (the first occurrence of retinopathy requiring laser therapy or vitrectomy, or a $30 \%$ decline in estimated GFR [eGFR], or need for renal replacement therapy) for the TZD arm, and hospitalisation for heart failure, pneumonia or shortness of breath, hospitalisation for any reason, revascularisation and fractures for both study arms. All outcomes except decline in eGFR and hospitalisation for any reason were adjudicated according to prespecified criteria, without knowledge of study-group allocation.

Serum calcium was measured at baseline, at 2 months and at the annual and end-of-study visits. Fasting lipids, serum creatinine and alanine aminotransferase (ALT) were measured at baseline and end-of-study visits. Fasting plasma glucose and $\mathrm{HbA}_{1 \mathrm{c}}$ were measured at baseline, after 1 year and at the end-of-study visits. All blood tests were assayed locally. To facilitate cross-site comparisons, if the upper limit of normal for the locally measured $\mathrm{HbA}_{1 \mathrm{c}}$ result was not $6 \%(42 \mathrm{mmol} / \mathrm{mol})$, the measured value was divided by the upper limit of normal and multiplied by $6 \% . \mathrm{HbA}_{1 \mathrm{c}}$ values measured using the International Federation of Clinical Chemistry or related methods were converted to the Diabetes Control and Complications Trial-National Glycohaemoglobin Standardisation Program (DCCT-NGSP) values using published regression equations [44].
Statistical analysis Sample size calculations showed that 16,000 participants would provide approximately 90\% power to detect a $20 \%$ or greater reduction in the primary outcome of TZDs vs placebo, assuming an annual event rate of $2 \%, 2$ years of recruitment, 5.5 years of follow-up, and a two-sided $\alpha$ between 0.025 and 0.05 . This sample size would include 10,888 people randomised to either rosiglitazone or placebo and would exclude a $30 \%$ excess of events with rosiglitazone compared with placebo using a one-sided $\alpha$ level of 0.0125 during a safety analysis after 4.5 years. The study would also have $90 \%$ power to detect a $26 \%$ reduction in mortality or serious cancer with vitamin D over 5.5 years and $18 \%$ over 10 years assuming an event rate of this composite outcome of $1 \%$ per year.

Data were collected, stored and analysed centrally at the Population Health Research Institute project office independent of the sponsor. Statistical analyses were conducted using SAS version 9.1 software (SAS Institute). All group comparisons were done according to the intention-to-treat approach. Kaplan-Meier and Cox regression analyses were planned. However, following early termination of the trial and prior to unblinding, the scientific committee determined that such analyses would be inappropriate because of the small numbers of outcomes. Characteristics of participants at baseline and at the end of the study are tabulated as means $\pm \mathrm{SD}$ or number (percentage) and end-of-study comparisons were made by Student's $t$ tests or $\chi^{2}$ tests. Incidence rates of primary outcomes, secondary outcomes and any safety events were calculated by dividing the number of individuals experiencing an event by the personyears of follow-up (from randomisation to the time of an event or censoring).

\section{Results}

The first participant was randomised in June 2009. By the end of January 2010 a total of 143 randomised individuals, 157 centres, and 18 countries were participating, and by the end of February when the US Senate report was released, this had risen rapidly to 204 participants, 202 centres, and 20 countries. By the time recruitment was suspended at the end of July 2010, 455 centres located in 33 countries were eligible to recruit participants. However, despite the addition of 253 centres with ethics approvals after February, the proportion of centres that were screening participants subsequently decreased (Fig. 1). Thus, a total of 1332 participants were ultimately randomised in only 175 of the 455 centres to the TZD arm (541 to placebo, 392 to pioglitazone, and 399 to rosiglitazone) and 1,221 to the vitamin D arm (614 to placebo and 607 to vitamin D). Figure 1 illustrates the 


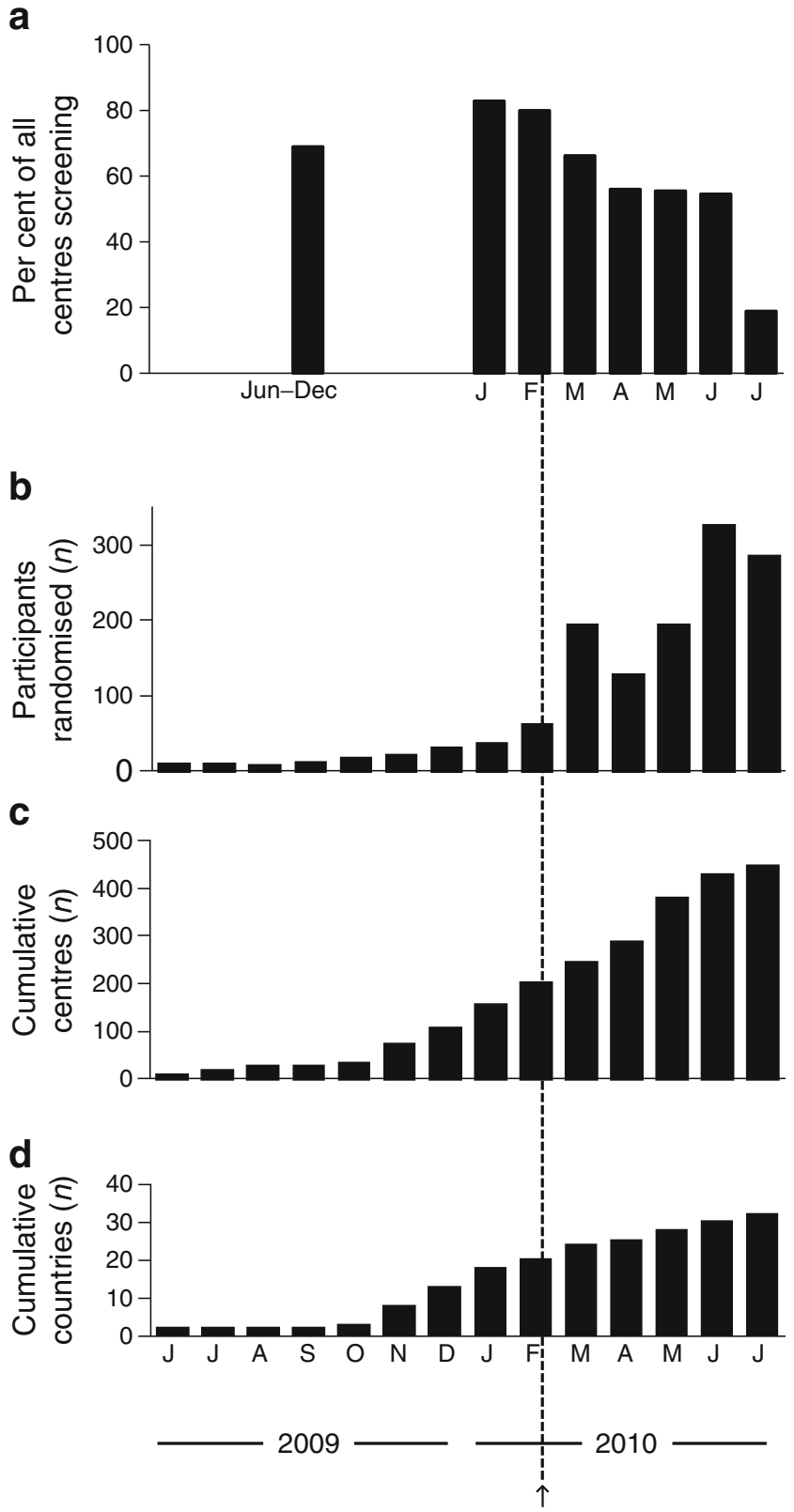

Fig. 1 Recruitment potential and activity are shown by calendar month (denoted by the first letter of the month on the $x$-axis). The panels illustrate: (a) the percentage of centres recruiting; (b) the numbers of participants randomised each month; (c) cumulative numbers of centres with ethics approval eligible to recruit; and (d) cumulative numbers of countries with regulatory approval for the trial. The arrow indicates the release date of the US Senate Report

numbers of participating countries, participating centres and randomised participants by month. During the trial, six participants died, two participants were lost-to-followup, and ten participants withdrew consent. All other participants were followed until the end of the study, and vital status was known for 1,320 (99.1\%) participants. The disposition of participants by treatment group is shown in Fig. 2a, b.
Baseline characteristics of participants were similar across allocated groups (Table 1). The mean age of participants was $66.4 \pm 6.6$ years, $41 \%$ were women and $35 \%$ had prior cardiovascular disease. The mean duration of diabetes was $8.8 \pm 6.9$ years and the mean $\mathrm{HbA}_{1 \mathrm{c}}$ was $7.4 \pm$ $0.9 \%(57 \pm 10 \mathrm{mmol} / \mathrm{mol})$. Mean duration of follow-up was 162 days (i.e. 590 person-years) for the TZD arm and 130 days (i.e. 546 person-years) for the vitamin D arm. Of the 1325 surviving participants contacted before it was announced that the trial would be stopped, $90 \%(n=1,187)$ and $91 \%(n=1,018)$ were at least $80 \%$ adherent to the TZD and vitamin D study drugs, respectively $(91 \%$ to placebo [ $n=487], 87 \%$ to pioglitazone [ $n=341]$, and $91 \%$ to rosiglitazone $[n=359] ; 92 \%$ to placebo $[n=519]$ and $91 \%$ to vitamin $\mathrm{D}[n=499])$. A mean of $2.2 \%$ of participants stopped the study drug per month before the Senate report was publicised, whereas a mean of $2.5 \%$ of participants stopped the study drug per month in the 3 months prior to the announcement of trial termination. Between that announcement and the end-of-study visit, participants were stopping the study drug at a high rate of $18 \%$ per month; thus by the end-of-study visit, $39 \%$ of participants had stopped the TZD study drug $(n=516)$ and $34 \%$ had stopped the vitamin D study drug $(n=417)$. The most common reasons for stopping the TZD study drug either temporarily or permanently during the trial were hearing that the trial was terminated $(56 \%, n=288)$, adverse events $(22 \%, n=115)$ and fear of adverse events $(12 \%, n=62)$. The most common reasons for stopping the vitamin D study drug were hearing the trial was terminated $(69 \%, n=288)$, adverse events $(13 \%, n=56)$ and fear of adverse events $(5 \%, n=21)$.

Adjudicated outcomes are presented in Table 2 and the outcomes as reported (i.e. prior to adjudication) are shown in Electronic supplementary material (ESM) Table 1 . The primary composite cardiovascular outcome occurred in five $(0.9 \%)$ participants in the placebo group and three $(0.4 \%)$ participants in the TZD group (two allocated to pioglitazone and one allocated to rosiglitazone). The primary outcome for the vitamin D study (allcause mortality or serious cancers) occurred in three $(0.5 \%)$ placebo group participants and two $(0.3 \%)$ vitamin D group participants.

Physical measurements, metabolic variables and use of concomitant glucose-lowering medications at the end of the trial are shown in Table 3. Compared with placebo, participants randomised to a TZD (pioglitazone and rosiglitazone groups combined) achieved lower $\mathrm{HbA}_{1 \mathrm{c}}$ (6.9\% vs $7.3 \%$ [ 52 vs $56 \mathrm{mmol} / \mathrm{mol}], p<0.001)$, fasting plasma glucose ( 7.2 vs $8.0 \mathrm{mmol} / \mathrm{l}, p<0.001)$ and ALT ( 25 vs $27 \mathrm{U} / 1, p=0.006)$, and increased their weight (88.0 vs $85.2 \mathrm{~kg}, p=0.008)$ and BMI (31.5 vs $\left.30.4 \mathrm{~kg} / \mathrm{m}^{2}, p=0.001\right)$. Compared with pioglitazone, the rosiglitazone group had 

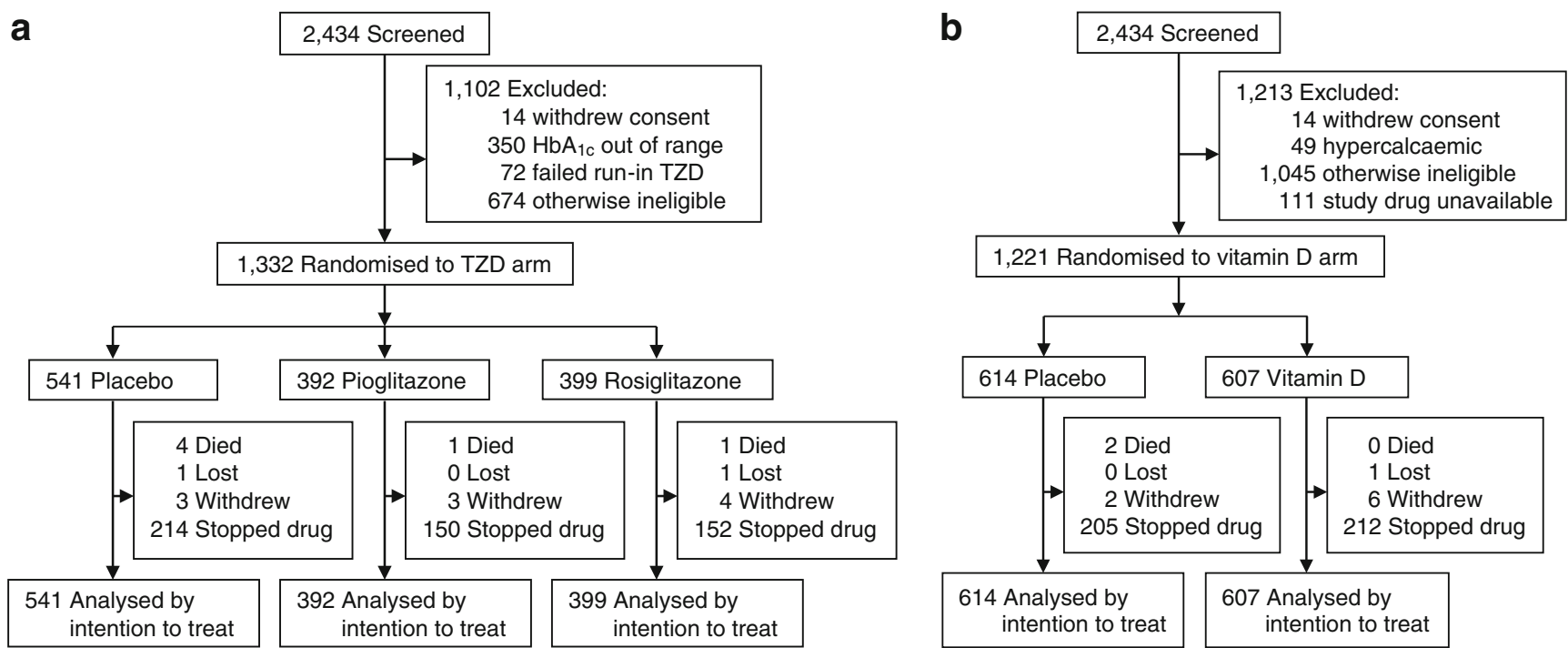

Fig. 2 Trial profiles of participants based on allocation to (a) the TZD arm, and (b) the vitamin D arm. Multiple reasons are possible for excluded or non-completed individuals. The 111 participants rando-

slightly higher $\mathrm{HbA}_{1 \mathrm{c}}(7.0 \%$ vs $6.8 \%$ [53 vs $51 \mathrm{mmol} / \mathrm{mol}$ ], $p=0.024)$, and also higher triacylglycerols $(2.10 \mathrm{vs}$ $1.67 \mathrm{mmol} / 1, p<0.001)$, and lower HDL-cholesterol (1.19 vs $1.27 \mathrm{mmol} / \mathrm{l}, p=0.003$ ) at the end of the trial. The use of statins, ACE inhibitors or angiotensin receptor blockers, anti-platelet agents, diuretics and nitrates were similar at the end of the trial (data not shown). Vitamin D did not affect physical measurements, biochemistry (including serum calcium) or concomitant medication use.

Severe hypoglycaemia (i.e. hypoglycaemia requiring assistance from another person, with either a documented plasma glucose $\leq 2.0 \mathrm{mmol} / 1$ or prompt recovery after oral carbohydrate, intravenous glucose, or glucagon administration) occurred in none of the participants in the placebo group, two $(0.5 \%)$ in the pioglitazone group and one $(0.3 \%)$ in the rosiglitazone group. Hospital admission for congestive heart failure occurred in one $(0.2 \%)$ participant in the placebo group, two $(0.5 \%)$ in the pioglitazone group and none in the rosiglitazone group. Fractures occurred in two $(0.4 \%)$ participants in the placebo group, two $(0.5 \%)$ in the pioglitazone group and three $(0.8 \%)$ in the rosiglitazone group. Severe adverse events were reported in seven placebo participants, five pioglitazone participants and two rosiglitazone participants, and in the vitamin D arm, by two placebo participants and nine vitamin D participants. Serious adverse events, tabulated in ESM Table 2, included two cardiovascular, three respiratory, two gastrointestinal, three genitourinary, one multi-organ failure, one pruritic allergic and two hypoglycaemic events. Each specific serious adverse event type occurred in only one person, except for hypoglycaemia which was reported in two participants. mised to the TZD arm were not randomised to the vitamin D arm because the vitamin D study drug was not available at the time of study termination

\section{Discussion}

The purpose of the TIDE trial was to elucidate the effect of TZDs on cardiovascular events while also elucidating the effect of vitamin D on cancer and death in people with type 2 diabetes and other cardiovascular risk factors. TIDE was designed to recruit 16,000 participants over 2 years and would have included 816 sites in 39 countries once all sites were activated. Based on the observed recruitment rates in early 2010, plans to add more sites, and ongoing support for continuation of the trial by the unblinded Independent Data Monitoring Committee, it is likely that recruitment would have rapidly increased until its completion in mid 2011. However, the heated political debate, global coverage and public controversy surrounding both the trial and rosiglitazone attenuated recruitment and led to randomisation of only 1,332 of the planned 16,000 participants by the time recruitment was stopped. Eight of these 1,332 suffered the composite primary outcome during a mean follow-up period of just 0.4 years of receiving TZD study drug - a number from which no conclusions can be drawn. The TZDs both reduced $\mathrm{HbA}_{1 \mathrm{c}}$ and ALT levels and increased weight, whereas pioglitazone but not rosiglitazone modestly reduced triacylglycerol and raised HDLcholesterol levels compared with placebo.

Uncertainty will persist regarding clinically relevant risks and benefits of either rosiglitazone or pioglitazone. Indeed, clinical equipoise regarding the cardiovascular effects of the TZDs prompted the American Heart Association and the American College of Cardiology to advocate jointly the conduct of definitive cardiovascular outcomes trials such as TIDE as recently as 2010 [22]. Such trials are 
Table 1 Participant characteristics at baseline

\begin{tabular}{|c|c|c|c|c|c|}
\hline \multirow[t]{2}{*}{ Characteristic } & \multicolumn{3}{|l|}{ TZD arm } & \multicolumn{2}{|c|}{ Vitamin D arm } \\
\hline & $\begin{array}{l}\text { Placebo } \\
n=541\end{array}$ & $\begin{array}{l}\text { Pioglitazone } \\
n=392\end{array}$ & $\begin{array}{l}\text { Rosiglitazone } \\
n=399\end{array}$ & $\begin{array}{l}\text { Placebo } \\
n=614\end{array}$ & $\begin{array}{l}\text { Vitamin D } \\
n=607\end{array}$ \\
\hline Female & $220(41)$ & $167(43)$ & $161(40)$ & $254(41)$ & $245(40)$ \\
\hline Age (years) & $66.4 \pm 6.8$ & $66.3 \pm 6.6$ & $66.5 \pm 6.4$ & $66.6 \pm 6.3$ & $66.7 \pm 6.7$ \\
\hline Duration of diabetes (years) & $8.7 \pm 6.9$ & $8.5 \pm 6.3$ & $9.1 \pm 7.3$ & $8.9 \pm 6.9$ & $8.9 \pm 7.0$ \\
\hline Weight $(\mathrm{kg})$ & $85.2 \pm 17.9$ & $85.4 \pm 18.2$ & $86.0 \pm 18.3$ & $85.8 \pm 18.2$ & $85.9 \pm 18.1$ \\
\hline BMI $\left(\mathrm{kg} / \mathrm{m}^{2}\right)$ & $30.4 \pm 5.2$ & $30.6 \pm 5.4$ & $30.7 \pm 5.3$ & $30.7 \pm 5.3$ & $30.6 \pm 5.3$ \\
\hline Waist/hip ratio & $0.98 \pm 0.09$ & $0.98 \pm 0.08$ & $0.98 \pm 0.08$ & $0.98 \pm 0.08$ & $0.98 \pm 0.09$ \\
\hline Systolic blood pressure (mmHg) & $137 \pm 18$ & $139 \pm 17$ & $138 \pm 17$ & $138 \pm 18$ & $137 \pm 17$ \\
\hline Diastolic blood pressure (mmHg) & $80 \pm 11$ & $80 \pm 10$ & $81 \pm 11$ & $80 \pm 11$ & $80 \pm 10$ \\
\hline Heart rate (beats per minute) & $72 \pm 11$ & $72 \pm 11$ & $71 \pm 11$ & $71 \pm 11$ & $72 \pm 11$ \\
\hline \multicolumn{6}{|l|}{ Race/ethnicity } \\
\hline White & $330(61)$ & $241(62)$ & $255(64)$ & $379(62)$ & $378(62)$ \\
\hline South Asian & $63(12)$ & $46(12)$ & $48(12)$ & $64(10)$ & $62(10)$ \\
\hline Black & $45(8.3)$ & $35(8.9)$ & $26(6.5)$ & $56(9.1)$ & $48(7.9)$ \\
\hline Latin American & $33(6.1)$ & $26(6.6)$ & $24(6.0)$ & $37(6.0)$ & $46(7.6)$ \\
\hline East Asian & $12(2.3)$ & $6(1.5)$ & $7(1.8)$ & $10(1.6)$ & $9(1.5)$ \\
\hline Other & $57(11)$ & $38(10)$ & $39(10)$ & $68(11)$ & $63(10)$ \\
\hline \multicolumn{6}{|l|}{ Education } \\
\hline$\leq 12$ years & $309(57)$ & $234(60)$ & $231(58)$ & $352(57)$ & $351(58)$ \\
\hline$>12$ years & $231(43)$ & $158(40)$ & $168(42)$ & $262(43)$ & $255(42)$ \\
\hline Regular alcohol use & $173(32)$ & $143(37)$ & $131(33)$ & $210(34)$ & $214(35)$ \\
\hline Current tobacco use & $64(12)$ & $46(12)$ & $56(14)$ & $75(12)$ & $76(13)$ \\
\hline $\mathrm{BMI}>30 \mathrm{~kg} / \mathrm{m}^{2}$ & $258(48)$ & $187(48)$ & $190(48)$ & $297(48)$ & $288(47)$ \\
\hline Hypertension & $475(88)$ & $346(88)$ & $353(89)$ & $545(89)$ & $527(87)$ \\
\hline Dyslipidaemia & $408(75)$ & $299(76)$ & 309 (77) & $467(76)$ & $468(77)$ \\
\hline Cardiovascular disease & $187(35)$ & $131(33)$ & $142(36)$ & $209(34)$ & $204(34)$ \\
\hline Myocardial infarction & $74(14)$ & $54(14)$ & $51(13)$ & $80(13)$ & $78(13)$ \\
\hline Stroke & $19(3.5)$ & $15(3.8)$ & $15(3.8)$ & $27(4.4)$ & $17(2.8)$ \\
\hline Heart failure (NYHA I only) & $14(2.6)$ & $11(2.8)$ & $13(3.3)$ & $12(2.0)$ & $7(1.2)$ \\
\hline Laser/vitrectomy for retinopathy & $12(2.2)$ & $9(2.3)$ & $9(2.3)$ & $20(3.3)$ & $10(1.6)$ \\
\hline Cancer & $32(5.9)$ & $23(5.9)$ & $24(6.0)$ & $33(5.4)$ & $42(6.9)$ \\
\hline Osteoporosis & $15(2.8)$ & $10(2.6)$ & $9(2.3)$ & $14(2.3)$ & $18(3.0)$ \\
\hline Fracture & $75(14)$ & $45(12)$ & $60(15)$ & $89(15)$ & $85(14)$ \\
\hline Glucose-lowering medication & $493(91)$ & $360(92)$ & $374(94)$ & $574(94)$ & $551(91)$ \\
\hline Biguanide & $442(82)$ & $313(80)$ & $325(82)$ & $499(81)$ & $488(80)$ \\
\hline Sulfonylurea & $248(46)$ & $188(48)$ & $209(52)$ & $286(47)$ & $293(48)$ \\
\hline TZD & $26(4.8)$ & $17(4.3)$ & $17(4.3)$ & $29(4.7)$ & $29(4.8)$ \\
\hline DPP4 inhibitor & $15(2.8)$ & $8(2.0)$ & $14(3.5)$ & $15(2.4)$ & $19(3.1)$ \\
\hline Other & $12(2.2)$ & $11(2.8)$ & $7(1.8)$ & $16(2.6)$ & $11(1.8)$ \\
\hline Statin & $353(65)$ & $263(67)$ & $265(66)$ & $413(67)$ & $395(65)$ \\
\hline ACE inhibitor and/or ARB & $401(74)$ & $297(76)$ & $285(71)$ & $463(75)$ & $441(73)$ \\
\hline Thiazide diuretic & $167(31)$ & $115(29)$ & $122(31)$ & $198(32)$ & $181(30)$ \\
\hline Other diuretic & $51(9.4)$ & $34(8.7)$ & $45(11.3)$ & $48(7.8)$ & $65(10.7)$ \\
\hline Antiplatelet agent & $306(57)$ & $214(55)$ & $220(55)$ & $329(54)$ & $356(59)$ \\
\hline Nitrate & $33(6.1)$ & $23(5.9)$ & $17(4.3)$ & $34(5.5)$ & $30(4.9)$ \\
\hline Vitamin D supplement & $57(11)$ & $47(12)$ & $51(13)$ & $71(12)$ & $78(13)$ \\
\hline \multicolumn{6}{|l|}{$\mathrm{HbA}_{1 \mathrm{c}}$} \\
\hline$\%$ & $7.3 \pm 0.9$ & $7.4 \pm 0.8$ & $7.4 \pm 0.9$ & $7.4 \pm 0.9$ & $7.3 \pm 0.9$ \\
\hline $\mathrm{mmol} / \mathrm{mol}$ & $56 \pm 10$ & $57 \pm 9$ & $57 \pm 10$ & $57 \pm 10$ & $56 \pm 9$ \\
\hline
\end{tabular}


Table 1 (continued)

\begin{tabular}{|c|c|c|c|c|c|}
\hline \multirow[t]{2}{*}{ Characteristic } & \multicolumn{3}{|l|}{ TZD arm } & \multicolumn{2}{|c|}{ Vitamin D arm } \\
\hline & $\begin{array}{l}\text { Placebo } \\
n=541\end{array}$ & $\begin{array}{l}\text { Pioglitazone } \\
n=392\end{array}$ & $\begin{array}{l}\text { Rosiglitazone } \\
n=399\end{array}$ & $\begin{array}{l}\text { Placebo } \\
n=614\end{array}$ & $\begin{array}{l}\text { Vitamin D } \\
n=607\end{array}$ \\
\hline Fasting plasma glucose $(\mathrm{mmol} / \mathrm{l})$ & $7.9 \pm 2.2$ & $7.9 \pm 2.2$ & $7.9 \pm 2.2$ & $7.9 \pm 2.1$ & $7.8 \pm 2.1$ \\
\hline Serum creatinine $(\mu \mathrm{mol} / \mathrm{l})$ & $83 \pm 26$ & $81 \pm 23$ & $84 \pm 27$ & $82 \pm 25$ & $84 \pm 25$ \\
\hline $\operatorname{ALT}(\mathrm{U} / 1)$ & $28 \pm 15$ & $28 \pm 15$ & $28 \pm 13$ & $28 \pm 15$ & $27 \pm 13$ \\
\hline Total cholesterol (mmol/l) & $4.61 \pm 1.11$ & $4.53 \pm 1.09$ & $4.53 \pm 1.17$ & $4.53 \pm 1.09$ & $4.53 \pm 1.11$ \\
\hline Triacylglycerols (mmol/l) & $1.83 \pm 1.22$ & $1.91 \pm 1.25$ & $1.92 \pm 1.11$ & $1.92 \pm 1.41$ & $1.84 \pm 0.97$ \\
\hline HDL-cholesterol (mmol/l) & $1.19 \pm 0.36$ & $1.19 \pm 0.31$ & $1.17 \pm 0.31$ & $1.17 \pm 0.34$ & $1.19 \pm 0.34$ \\
\hline LDL-cholesterol (mmol/l) & $2.62 \pm 0.98$ & $2.56 \pm 0.91$ & $2.54 \pm 0.96$ & $2.54 \pm 0.91$ & $2.56 \pm 0.96$ \\
\hline Serum calcium $(\mathrm{mmol} / \mathrm{l})$ & $2.35 \pm 0.13$ & $2.35 \pm 0.13$ & $2.35 \pm 0.13$ & $2.35 \pm 0.13$ & $2.35 \pm 0.13$ \\
\hline
\end{tabular}

Data are presented as mean \pm SD or $n(\%)$

Regular alcohol use: at least once per week

Cardiovascular disease: myocardial infarction; stroke; stable or unstable angina; valvular heart disease; arrhythmia; cardiac arrest; heart failure; coronary, carotid or peripheral revascularisation; amputation or intermittent claudication

ACE, angiotensin-converting enzyme; ARB, angiotensin 2 receptor blocker; DPP4, dipeptidylpeptidase 4; NYHA, New York Heart Association

Table 2 Clinical events

\begin{tabular}{|c|c|c|c|c|c|c|c|c|c|c|}
\hline \multirow[t]{3}{*}{ Event } & \multicolumn{6}{|c|}{ TZD arm } & \multicolumn{4}{|c|}{ Vitamin D arm } \\
\hline & \multicolumn{2}{|c|}{$\begin{array}{l}\text { Placebo }(n=541 \\
[237 \text { person-years }])\end{array}$} & \multicolumn{2}{|c|}{$\begin{array}{l}\text { Pioglitazone }(n=392 \\
[174 \text { person-years }])\end{array}$} & \multicolumn{2}{|c|}{$\begin{array}{l}\text { Rosiglitazone }(n=399 \\
[178 \text { person-years }])\end{array}$} & \multicolumn{2}{|c|}{$\begin{array}{l}\text { Placebo }(n=614 \\
[275 \text { person-years }])\end{array}$} & \multicolumn{2}{|c|}{$\begin{array}{l}\text { Vitamin D }(n=607 \\
[271 \text { person-years }])\end{array}$} \\
\hline & $n$ & Rate $^{a}$ & $n$ & Rate $^{a}$ & $n$ & Rate $^{a}$ & $n$ & Rate $^{a}$ & $n$ & Rate $^{\mathrm{a}}$ \\
\hline Primary cardiovascular outcome & 5 & 2.1 & 2 & 1.1 & 1 & 0.5 & 3 & 1.3 & 2 & 0.9 \\
\hline Cardiovascular death & 1 & & 0 & & 0 & & 1 & & 0 & \\
\hline Non-fatal myocardial infarction & 2 & & 0 & & 1 & & 1 & & 1 & \\
\hline Non-fatal stroke & 2 & & 2 & & 0 & & 1 & & 1 & \\
\hline Any revascularisation & 6 & 2.5 & 3 & 1.7 & 5 & 2.8 & 7 & 3.2 & 5 & 2.3 \\
\hline Hospitalisation for heart failure & 1 & & 2 & & 0 & & 0 & & 2 & \\
\hline Hospitalisation for dyspnoea & 0 & & 1 & & 2 & & 0 & & 1 & \\
\hline Hospitalisation for pneumonia & 0 & & 1 & & 0 & & 0 & & 0 & \\
\hline Hospitalisation for any reason & 31 & 13.5 & 16 & 9.3 & 24 & 13.9 & 19 & 8.8 & 32 & 15.3 \\
\hline Death or serious cancer & 6 & 2.5 & 3 & 1.7 & 1 & 0.5 & 3 & 1.3 & 2 & 0.9 \\
\hline All death & 4 & & 1 & & 1 & & 2 & & 0 & \\
\hline Serious cancer & 2 & & 2 & & 0 & & 1 & & 2 & \\
\hline Composite microvascular outcome & 21 & 8.8 & 8 & 4.5 & 9 & 5 & 18 & 8.2 & 18 & 8.3 \\
\hline Retinal photocoagulation & 1 & & 0 & & 0 & & 0 & & 0 & \\
\hline Vitrectomy & 0 & & 0 & & 0 & & 0 & & 0 & \\
\hline Renal replacement therapy & 0 & & 0 & & 0 & & 0 & & 0 & \\
\hline$\geq 30 \%$ decline in eGFR & 20 & & 8 & & 9 & & 18 & & 18 & \\
\hline Severe hypoglycaemia & 0 & & 2 & & 1 & & 0 & & 3 & \\
\hline Fracture & 2 & & 2 & & 3 & & 3 & & 3 & \\
\hline
\end{tabular}

Number of individuals randomised is shown in the column headings, with person-years in parentheses

Severe hypoglycaemia: hypoglycaemia requiring assistance from another person and either documented plasma glucose $\leq 2.0 \mathrm{mmol} / 1 \mathrm{or}$ prompt recovery after oral carbohydrate, intravenous glucose, or glucagon administration

${ }^{\mathrm{a}}$ Incidence rates are shown per 100 person-years 
Table 3 Physical measurements, biochemistry and diabetes medication use at study end

\begin{tabular}{|c|c|c|c|c|c|}
\hline \multirow[t]{2}{*}{ Measure } & \multicolumn{3}{|l|}{ TZD arm } & \multicolumn{2}{|c|}{ Vitamin D arm } \\
\hline & Placebo & Pioglitazone & Rosiglitazone & Placebo & Vitamin D \\
\hline \multicolumn{6}{|l|}{ Physical measurements } \\
\hline Weight (kg) & $85.2 \pm 17.1 * *$ & $88.1 \pm 18.0$ & $87.9 \pm 18.2$ & $86.9 \pm 18.1$ & $86.9 \pm 17.6$ \\
\hline BMI $\left(\mathrm{kg} / \mathrm{m}^{2}\right)$ & $30.4 \pm 5.3^{* *}$ & $31.6 \pm 6.0$ & $31.4 \pm 5.6$ & $31.1 \pm 5.7$ & $30.9 \pm 5.5$ \\
\hline Waist/hip ratio & $0.97 \pm 0.08$ & $0.97 \pm 0.08$ & $0.97 \pm 0.09$ & $0.97 \pm 0.08$ & $0.97 \pm 0.08$ \\
\hline Systolic blood pressure (mmHg) & $134 \pm 17$ & $135 \pm 17$ & $135 \pm 17$ & $135 \pm 17$ & $134 \pm 16$ \\
\hline Diastolic blood pressure $(\mathrm{mmHg})$ & $78 \pm 10$ & $78 \pm 10$ & $78 \pm 11$ & $78 \pm 10$ & $78 \pm 10$ \\
\hline Heart rate & $72 \pm 12$ & $71 \pm 10$ & $71 \pm 12$ & $71 \pm 11$ & $71 \pm 11$ \\
\hline \multicolumn{6}{|l|}{ Biochemical measurements } \\
\hline $\mathrm{HbA}_{1 \mathrm{c}}(\%)$ & $7.3 \pm 1.1^{* * *}$ & $6.8 \pm 0.9^{\dagger}$ & $7.0 \pm 0.9$ & $7.0 \pm 1.0$ & $7.1 \pm 1.0$ \\
\hline $\mathrm{HbA}_{1 \mathrm{c}}(\mathrm{mmol} / \mathrm{mol})$ & $56 \pm 12 * * *$ & $51 \pm 10^{\dagger}$ & $53 \pm 10$ & $53 \pm 11$ & $54 \pm 11$ \\
\hline Fasting plasma glucose (mmol/l) & $8.0 \pm 2.6^{* * *}$ & $7.2 \pm 2.2$ & $7.2 \pm 2.3$ & $7.5 \pm 2.3$ & $7.5 \pm 2.4$ \\
\hline Serum creatinine $(\mu \mathrm{mol} / \mathrm{l})$ & $84 \pm 30$ & $83 \pm 25$ & $86 \pm 26$ & $83 \pm 24$ & $86 \pm 31$ \\
\hline $\operatorname{ALT}(\mathrm{U} / 1)$ & $27 \pm 14 * *$ & $24 \pm 11$ & $25 \pm 12$ & $25 \pm 13$ & $25 \pm 12$ \\
\hline Total cholesterol (mmol/l) & $4.53 \pm 1.09$ & $4.58 \pm 1.11$ & $4.71 \pm 1.17$ & $4.56 \pm 1.14$ & $4.64 \pm 1.09$ \\
\hline Triacylglycerols (mmol/l) & $1.82 \pm 1.02$ & $1.67 \pm 0.99^{\dagger \dagger \dagger}$ & $2.10 \pm 1.30$ & $1.83 \pm 1.08$ & $1.88 \pm 1.12$ \\
\hline HDL-cholesterol (mmol/l) & $1.19 \pm 0.36$ & $1.27 \pm 0.34^{\dagger \dagger}$ & $1.19 \pm 0.36$ & $1.22 \pm 0.34$ & $1.22 \pm 0.34$ \\
\hline LDL-cholesterol (mmol/l) & $2.56 \pm 0.93$ & $2.62 \pm 0.96$ & $2.64 \pm 0.98$ & $2.56 \pm 0.93$ & $2.64 \pm 0.96$ \\
\hline Serum calcium (mmol/l) & $2.35 \pm 0.13$ & $2.35 \pm 0.13$ & $2.35 \pm 0.10$ & $2.35 \pm 0.10$ & $2.35 \pm 0.13$ \\
\hline \multicolumn{6}{|l|}{ Glucose-lowering medication } \\
\hline Biguanide & $422(83)$ & $287(78)$ & $300(81)$ & $490(83)$ & $460(79)$ \\
\hline Sulfonylurea & $238(47)$ & $159(43)$ & $184(50)$ & $266(45)$ & $273(47)$ \\
\hline Non-study TZD & $6(1.2)$ & $6(1.6)$ & $4(1.1)$ & $5(0.8)$ & $9(1.5)$ \\
\hline DPP4 inhibitor & $19(3.7)$ & $11(3.0)$ & $13(3.5)$ & $22(3.7)$ & $19(3.3)$ \\
\hline Insulin & $3(0.6)$ & $1(0.3)$ & $2(0.5)$ & $2(0.3)$ & $4(0.7)$ \\
\hline Other & $10(2.0)$ & $9(2.5)$ & $6(1.6)$ & $13(2.2)$ & $9(1.5)$ \\
\hline
\end{tabular}

Data are presented as mean $\pm \mathrm{SD}$ or $n(\%)$

For glucose-lowering medication use, denominators are the 1,249 TZD arm participants and the 1,175 vitamin D arm participants who provided medication data at the final visit

${ }^{* *} p<0.01$ and ${ }^{* * *} p<0.001$ for placebo vs TZDs (pioglitazone and rosiglitazone groups combined); ${ }^{\dagger} p<0.05,{ }^{\dagger \dagger} p<0.01$ and ${ }^{\dagger \dagger \dagger} p<0.001$ for pioglitazone vs rosiglitazone

DPP4, dipeptidylpeptidase

those that are large and continue for long enough to generate reliable results by accruing more than 1,000 primary outcomes [45-47]. Without such trials, some therapies that are now known to be harmful would have been promoted because they were considered to be beneficial based on weaker evidence (e.g. suppression of ventricular premature beats after a myocardial infarction [48]) whereas other therapies that are now known to be beneficial would have been abandoned because they were considered to be harmful based on weaker evidence (e.g. lowering of systolic blood pressure in the elderly [49] and beta-blockers in heart failure [50]).

As with the TZDs, no conclusion regarding the effects of vitamin D on cancers and mortality can be drawn. Previous randomised trials were not designed to assess extra-skeletal effects, or used doses of vitamin D that were likely inadequate to promote extra-skeletal effects [37, 39]. Nevertheless, these data and data from physiological studies have been used to actively promote its use for such indications. An ongoing trial of 20,000 people (ClinicalTrials.gov NCT01169259) is likely to resolve this uncertainty.

The strengths of TIDE were its placebo-controlled design, large size, inclusion of a research question regarding vitamin $\mathrm{D}$ in addition to the TZD questions, safety oversight by an independent data monitoring committee and independent scientific leadership. Its main weakness was its timing. Had it been initiated earlier it is likely that its results would have pre-empted premature conclusions and claims by various organisations and 
individuals regarding the efficacy and safety of rosiglitazone or pioglitazone. Indeed, the results would have provided clear evidence to inform medical care. The history of TIDE therefore highlights the importance of conducting well-designed outcomes trials such as TIDE early in the lifecycle of drugs that are likely to be used for the ongoing treatment of chronic diseases such as diabetes.

Contribution statement ZP and HCG had full access to all of the data in the study and take responsibility for the integrity of the data and the accuracy of the data analysis. HCG, JB, SY, ZP, GD, RD, RH, JLP, AR, MCR, LER and BZ contributed to study concept and design. RA contributed to data analysis. ZP and HCG contributed to drafting of the manuscript. JB, GD, RD, JH, JLP, AR, MCR, LER, BZ, RA and SY contributed to critical revision of the manuscript for important intellectual content. All authors approved the final version.

Duality of interest H. C. Gerstein, S. Yusuf and Z. Punthakee's institution received funding to conduct the TIDE trial from GlaxoSmithKline, manufacturer of rosiglitazone. Z. Punthakee has received honoraria for advice and speaking from GlaxoSmithKline, Boehringer Ingelheim, Lilly, Merck Frosst, NovoNordisk and sanofiaventis. G. Dagenais has received consulting and lecture fees from GlaxoSmithKline, Boehringer Ingelheim and sanofi-aventis and grant support from sanofi-aventis. R. Diaz has received consulting fees or honoraria and other research support from Bristol-Myers Squibb. R. Holman has received research support from Amylin, Bayer, Merck and Novartis, attended advisory boards with Amylin, Lilly, Merck, Novartis and Novo Nordisk, and given lectures supported by Bayer, Lilly, Merck and Merck Serono. A. Ramachandran has received honoraria for advice and speaking from sanofi-aventis, MSD and Lilly. M. C. Riddle has received honoraria for consulting and/or speaking from Amylin, Lilly, Novo Nordisk and sanofi-aventis, and also research grant support through his institution from Amylin, Lilly, GlaxoSmithKline and sanofi-aventis. L. E. Rydén has received honoraria for advice and lectures by AstraZeneca, Roche and Bristol-Myers Squibb. B. Zinman has received honoraria for consulting from GlaxoSmithKline and Lilly. S. Yusuf has received consulting fees from Boehringer Ingelheim, sanofi-aventis, Novartis, AstraZeneca, Bristol-Myers Squibb and GlaxoSmithKline. H. C. Gerstein has received honoraria for consulting and speaking from GlaxoSmithKline, sanofiaventis, Lilly, Novo Nordisk, Bayer, Merck, Johnson and Johnson, Roche, Abbot and AstraZeneca. The remaining authors declare that they have no duality of interest associated with this manuscript. Funding and supply of the investigational medicines for this trial was provided by GlaxoSmithKline, the manufacturer of rosiglitazone. In collaboration with H. C. Gerstein, S. Yusuf and an international scientific committee, the sponsor GlaxoSmithKline had input to the design of the trial. The sponsor reviewed the manuscript and provided minor comments.

\section{References}

1. Phung OJ, Scholle JM, Talwar M, Coleman CI (2010) Effect of noninsulin antidiabetic drugs added to metformin therapy on glycemic control, weight gain, and hypoglycemia in type 2 diabetes. JAMA 303:1410-1418

2. Gerstein HC, Yusuf S, Bosch J et al (2006) Effect of rosiglitazone on the frequency of diabetes in patients with impaired glucose tolerance or impaired fasting glucose: a randomised controlled trial. Lancet 368:1096-1105

3. DeFronzo RA, Tripathy D, Schwenke DC et al (2011) Pioglitazone for diabetes prevention in impaired glucose tolerance. N Engl J Med 364:1104-1115

4. Kahn SE, Haffner SM, Heise MA et al (2006) Glycemic durability of rosiglitazone, metformin, or glyburide monotherapy. N Engl J Med 355:2427-2443

5. Tan M, Johns D, Gonzalez GG et al (2004) Effects of pioglitazone and glimepiride on glycemic control and insulin sensitivity in Mexican patients with type 2 diabetes mellitus: a multicenter, randomized, double-blind, parallel-group trial. Clin Ther 26:680-693

6. Qayyum R, Adomaityte J (2006) A meta-analysis of the effect of thiazolidinediones on blood pressure. J Clin Hypertens (Greenwich) 8:19-28

7. Sarafidis PA, Stafylas PC, Georgianos PI, Saratzis AN, Lasaridis AN (2010) Effect of thiazolidinediones on albuminuria and proteinuria in diabetes: a meta-analysis. Am J Kidney Dis 55:835-847

8. Dagenais GR, Gerstein HC, Holman R et al (2008) Effects of ramipril and rosiglitazone on cardiovascular and renal outcomes in people with impaired glucose tolerance or impaired fasting glucose: results of the Diabetes REduction Assessment with ramipril and rosiglitazone Medication (DREAM) trial. Diabetes Care 31:1007-1014

9. Lachin JM, Viberti G, Zinman B et al (2011) Renal function in type 2 diabetes with rosiglitazone, metformin, and glyburide monotherapy. Clin J Am Soc Nephrol 6:1032-1040

10. Vijay SK, Mishra M, Kumar H, Tripathi K (2009) Effect of pioglitazone and rosiglitazone on mediators of endothelial dysfunction, markers of angiogenesis and inflammatory cytokines in type-2 diabetes. Acta Diabetol 46:27-33

11. Riche DM, Valderrama R, Henyan NN (2007) Thiazolidinediones and risk of repeat target vessel revascularization following percutaneous coronary intervention: a meta-analysis. Diabetes Care 30:384-388

12. Lonn EM, Gerstein HC, Sheridan P et al (2009) Effect of ramipril and of rosiglitazone on carotid intima-media thickness in people with impaired glucose tolerance or impaired fasting glucose: STARR (STudy of Atherosclerosis with Ramipril and Rosiglitazone). J Am Coll Cardiol 53:2028-2035

13. Mazzone T, Meyer PM, Feinstein SB et al (2006) Effect of pioglitazone compared with glimepiride on carotid intimamedia thickness in type 2 diabetes: a randomized trial. JAMA 296:2572-2581

14. Sidhu JS, Kaposzta Z, Markus HS, Kaski JC (2004) Effect of rosiglitazone on common carotid intima-media thickness progression in coronary artery disease patients without diabetes mellitus. Arterioscler Thromb Vasc Biol 24:930-934

15. Choi D, Kim SK, Choi SH et al (2004) Preventative effects of rosiglitazone on restenosis after coronary stent implantation in patients with type 2 diabetes. Diabetes Care 27:2654-2660

16. Nissen SE, Nicholls SJ, Wolski K et al (2008) Comparison of pioglitazone vs glimepiride on progression of coronary atherosclerosis in patients with type 2 diabetes: the PERISCOPE randomized controlled trial. JAMA 299:1561-1573

17. Inzucchi SE, Masoudi FA, Wang Y et al (2005) Insulin-sensitizing antihyperglycemic drugs and mortality after acute myocardial infarction: insights from the National Heart Care Project. Diabetes Care 28:1680-1689

18. Masoudi FA, Inzucchi SE, Wang Y, Havranek EP, Foody JM, Krumholz HM (2005) Thiazolidinediones, metformin, and outcomes in older patients with diabetes and heart failure: an observational study. Circulation 111:583-590

19. Frye RL, August P, Brooks MM et al (2009) A randomized trial of therapies for type 2 diabetes and coronary artery disease. N Engl J Med 360:2503-2515 
20. Home PD, Pocock SJ, Beck-Nielsen H et al (2009) Rosiglitazone evaluated for cardiovascular outcomes in oral agent combination therapy for type 2 diabetes (RECORD): a multicentre, randomised, open-label trial. Lancet 373:2125-2135

21. Dormandy JA, Charbonnel B, Eckland DJ et al (2005) Secondary prevention of macrovascular events in patients with type 2 diabetes in the PROactive Study (PROspective pioglitAzone Clinical Trial In macroVascular Events): a randomised controlled trial. Lancet 366:1279-1289

22. Kaul S, Bolger AF, Herrington D, Giugliano RP, Eckel RH (2010) Thiazolidinedione drugs and cardiovascular risks: a science advisory from the American Heart Association and American College of Cardiology Foundation. Circulation 121:1868-1877

23. Yki-Jarvinen H (2005) The PROactive Study: some answers, many questions. Lancet 366:1241-1242

24. Freemantle N (2005) How well does the evidence on pioglitazone back up researchers' claims for a reduction in macrovascular events? BMJ 331:836-838

25. Lago RM, Singh PP, Nesto RW (2007) Congestive heart failure and cardiovascular death in patients with prediabetes and type 2 diabetes given thiazolidinediones: a meta-analysis of randomised clinical trials. Lancet 370:1129-1136

26. Mannucci E, Monami M, Di BM et al (2010) Cardiac safety profile of rosiglitazone: a comprehensive meta-analysis of randomized clinical trials. Int J Cardiol 143:135-140

27. Nagajothi N, Adigopula S, Balamuthusamy S et al (2008) Pioglitazone and the risk of myocardial infarction and other major adverse cardiac events: a meta-analysis of randomized, controlled trials. Am J Ther 15:506-511

28. Richter B, Bandeira-Echtler E, Bergerhoff K, Clar C, Ebrahim SH (2006) Pioglitazone for type 2 diabetes mellitus Cochrane Database Syst Rev 4:CD006060. doi:10.1002/14651858. CD006060.pub2

29. Richter B, Bandeira-Echtler E, Bergerhoff K, Clar C, Ebrahim SH (2007) Rosiglitazone for type 2 diabetes mellitus Cochrane Database Syst Rev 3:CD006063. doi:10.1002/14651858. CD006063.pub2

30. Food and Drug Administration briefing document: 13-14 July 2010 Meeting of the Endocrinologic and Metabolic Drugs Advisory Committee (2011). Available from www.fda.gov/ AdvisoryCommittees/CommitteesMeetingMaterials/Drugs/ EndocrinologicandMetabolicDrugs AdvisoryCommittee/ ucm191113.htm. Accessed 25 April 2011

31. Scragg R, Sowers M, Bell C (2004) Serum 25-hydroxyvitamin D, diabetes, and ethnicity in the Third National Health and Nutrition Examination Survey. Diabetes Care 27:2813-2818

32. Holick MF (2010) Vitamin D: extraskeletal health. Endocrinol Metab Clin North Am 39:381-400

33. Cigolini M, Iagulli MP, Miconi V, Galiotto M, Lombardi S, Targher G (2006) Serum 25-hydroxyvitamin D3 concentrations and prevalence of cardiovascular disease among type 2 diabetic patients. Diabetes Care 29:722-724
34. Wang TJ, Pencina MJ, Booth SL et al (2008) Vitamin D deficiency and risk of cardiovascular disease. Circulation 117:503-511

35. Autier P, Gandini S (2007) Vitamin D supplementation and total mortality: a meta-analysis of randomized controlled trials. Arch Intern Med 167:1730-1737

36. Hsia J, Heiss G, Ren H et al (2007) Calcium/vitamin D supplementation and cardiovascular events. Circulation 115:846-854

37. Wactawski-Wende J, Kotchen JM, Anderson GL et al (2006) Calcium plus vitamin D supplementation and the risk of colorectal cancer. N Engl J Med 354:684-696

38. Chlebowski RT, Johnson KC, Kooperberg C et al (2008) Calcium plus vitamin $\mathrm{D}$ supplementation and the risk of breast cancer. $\mathrm{J}$ Natl Cancer Inst 100:1581-1591

39. Lappe JM, Travers-Gustafson D, Davies KM, Recker RR, Heaney RP (2007) Vitamin D and calcium supplementation reduces cancer risk: results of a randomized trial. Am J Clin Nutr 85:1586-1591

40. Harris G (2010) Research ties diabetes drug to heart woes. New York Times, 19 February 2010

41. Baucus M, Grassley C (2010) Staff report on GlaxoSmithKline and the diabetes drug Avandia 111-41. US Government Printing Office, Washington

42. Food and Drug Administration FDA Drug Safety Communication: ongoing review of Avandia (rosiglitazone) and cardiovascular safety (2010). Available from www.fda.gov/Drugs/DrugSafety/ PostmarketDrugSafetyInformationforPatientsandProviders/ ucm201418.htm. Accessed 9 May 2011

43. Mundy A, Corbett Dooren J (2010) FDA weighs halting avandia safety study. Wall Street Journal 19 April 2010

44. Weykamp C, John WG, Mosca A et al (2008) The IFCC reference measurement system for $\mathrm{HbA1c}$ : a 6-year progress report. Clin Chem 54:240-248

45. Gerstein HC, Yusuf S (2010) Clinical outcomes trials and the cardiovascular effects of thiazolidinediones: implications for the evaluation of antidiabetic drugs. Am Heart J 160:1-2

46. Baigent C, Peto R, Gray R, Parish S, Collins R (2010) Large-scale randomized evidence: trials and meta-analyses of trials. In: Warrell DA, Cox TM, Firth JD (eds) Oxford textbook of medicine, 5th edn. Oxford University Press, Oxford, pp 31-45

47. Yusuf S, Collins R, Peto R (1984) Why do we need some large, simple randomized trials? Stat Med 3:409-422

48. Echt DS, Liebson PR, Mitchell LB et al (1991) Mortality and morbidity in patients receiving encainide, flecainide, or placeboThe Cardiac Arrhythmia Suppression Trial. N Engl J Med 324:781-788

49. Anonymous (1991) Prevention of stroke by antihypertensive drug treatment in older persons with isolated systolic hypertension Final results of the Systolic Hypertension in the Elderly Program (SHEP) SHEP Cooperative Research Group. JAMA 265:3255-3264

50. Foody JM, Farrell MH, Krumholz HM (2002) Beta-blocker therapy in heart failure: scientific review. JAMA 287:883-889 